Proceedings

\title{
Analysis of New Strategies to Reach Nearly Zero Energy Buildings (nZEBs) ${ }^{\dagger}$
}

\author{
Jose Maria Santos-Herrero ${ }^{1, *}$, Jose Manuel Lopez-Guede ${ }^{2}$ and Ivan Flores ${ }^{1}$ \\ 1 Department of Thermal Engineering, Faculty of Engineering in Bilbao, University of the Basque Country \\ (UPV/EHU), Alda. Urkijo s/n, 48013 Bilbao, Spain; ivan.flores@ehu.eus \\ 2 Systems and Automatic Control Department, University Faculty of Engineering of Vitoria, University of \\ the Basque Country (UPV/EHU), c/Nieves Cano 12, 01006 Vitoria-Gasteiz, Spain; jm.lopez@ehu.eus \\ * Correspondence: jmsantos005@ikasle.ehu.es \\ + Presented at the 2nd International Research Conference on Sustainable Energy, Engineering, Materials and \\ Environment (IRCSEEME), Mieres, Spain, 25-27 September 2018.
}

Published: 7 November 2018

\begin{abstract}
The need to reduce $\mathrm{CO}_{2}$ emissions makes it necessary to review most areas of human activity because we are the main source of these emissions. In particular, the building sector is one of its main responsible. Through a State of the Art, several papers published in various scientific journals about nearly Zero Energy Building (nZEB) studies are reviewed. After carrying out an analysis of said documentation, it is considered that a new way of study can be developed with a multidisciplinary approach. For this, another series of articles are analyzed, where different advances in the field of building construction have been developed and are summarized. It is concluded that the Model Predictive Control (MPC) can also be a useful tool to optimize energy consumption in buildings, especially for public use, in order to achieve the goal of achieving nZEB, through the use of Renewable Energy Sources (RES).
\end{abstract}

Keywords: nearly-Zero Energy Buildings; building energy systems; energy-efficient buildings; model predictive control

\section{Introduction}

The risk of an environmental disaster requires our immediate action to avoid this situation which we are the first one responsible of. The main objective is to reduce $\mathrm{CO}_{2}$ emissions, what cause the greenhouse effect on our planet causing unprecedented climate changes and whose consequences are unpredictable. There are many areas of human activity where we can work to achieve this goal, but one of the main ones is the building sector. For example, the European building stock is responsible for $36 \%$ of the GreenHouse Gas emissions (GHG) because consumes approximately $40 \%$ of primary energy [1] (153/13-35). For that reason, in May 2010, the Energy Performance of Buildings Directive (EPBD 2010/31/EU) [1] was launched by European Parliament. This directive established a new concept called: nearly Zero Energy Building (nZEB) and in its Art.9 set down that EU Member States (MS) must ensure that all of the new buildings, starting 31st December 2020, will have to reach the standard nZEBs. This implies these constructions are very high-energy performance because they should cover the nearly zero energy (or at least a very low amount of it) required by on site or nearby energy production from Renewable Energy Source (RES) as it is defined in its Art.2.

The Directive EPBD 2010/31/EU is a recast of the Energy Performance of Building Directive 2002/91/EC (EPBD) [2]. European Union tried to address this issue by focusing their efforts on improving the energy performance of buildings by setting minimum requirements for building components and buildings, establishing nZEB as a political target. In fact, to avoid a further increase 
of the GHG levels, the European Union decided to issue several directives for the MS with the goal to encourage the reduction of energy consumption and promote the use of RES. The European legislation set out with it a cross-sectional framework of ambitious goals to achieve high energy performances in buildings. Subsequently, new directives have continued in the same direction and achieved ever more ambitious objectives, such as in 2012 [3] on energy efficiency that emphasizes key aspects such as smart grids. Also highlight another new framework in January 2014 [4], where goals are set in terms of climate and energy with horizon 2030. This new directive aims to reduce by $40 \%$ GHG with respect to 1990 levels, as well as improve energy efficiency by $30 \%$ to achieve a binding objective of at least $27 \%$ of renewable energies throughout the European Union.

\section{Literature Review about nZEBs}

Through the papers reviewed, one can observe the evolution of nZEBs in the last years. There are many researches that study the concept of nZEBs but they do it from a concrete point of view: architectural solutions, economic viability, new insulation materials, engineering level solutions, comparatives and etcetera. It can conclude that the most focus on the subject only from a specific discipline. That is, there are articles on architecture [5-10] where they study different passive strategies applicable during the design phase to get passive cooling systems: ground exchangers, evaporate cooling, night sky radiation or to take advantage of Solar shading efficiency or enhanced the building envelope features with new insulating materials: for instance, with Phase Change Materials (PCM) or in function of its Wall-Window Ratio (WWR). Some papers analyze and propose improvements from another technical point of view at the engineering level with different comparatives of Heating, Ventilation and Air Conditioning (HVAC) systems applying RES [11-13] or at the user's level, considering different comfort strategies [14]. And others priorize the economic point of view [14-20], analyzing the payback of the different options in order to find the most profitable solution. Although they are very interesting since they open the opportunity to continue improving in each area, it would be convenient to try to approach the subject from a more global point of view. A holistic treatment would facilitate the goal achievement in a simpler, faster and cheaper way.

\section{Overview of the Literature about MPC}

Through this review, one can observe the evolution of MPC for buildings in the last years. Starting from late 80s till nowadays, there are many researches which study the best way to develop a MPC and also multiple trials and implementations have been carried out.

García et al. [21] substantiated that MPC is an excellent control option because it takes into account the weather and occupancy forecast to find an optimal management of the energy. Cho et al. [22] probed strategies as a means of improving the energy efficiency of intermittently heated radiant floor heating systems. Roberts [23] analyzes passive and active measures in existing buildings. Kneifel [24] estimated life-cycle energy savings of energy efficiency actions in new commercial buildings. Oldewurtel et al. [25] performed climate controls using Stochastic model predictive control. Široký et al. [26] developed an experimental analysis of model predictive control. Cigler et al. [27] made a MPC implementation in a building. Fabietti et al. [28] controlled HVAC Systems via Explicit and Implicit MPC. Xiwang et al. [29] reviewed building energy modeling for control and operation. De Coninck et al. [30] developed a toolbox making validated grey-box building models and did practical implementation of MPC. Ruparathna et al. [31] summarized different energy efficiency improvement initiatives and defined a road map for improving the energy performance of operating commercial and institutional buildings. Harish et al. [32] reviewed modeling and control of building energy systems. Chandel et al. [33] showed codes, standards, regulations and energy efficiency alternatives. Santos-Herrero et al. [34] identified the factors which have influenced on any building energy system. During the years 2015-2016, some implementations of MPC in different locations and types of building were realized: Carrascal et al. [35] in a dwelling building in the Basque Country (Spain), Ascione et al. [36] in a residential building in Naples (Italy), Hu et al. [37] in a public building in California (USA), Sturzenegger et al. [38] in a office building in Allschwil (Switzerland) 
and Vaccarini et al. [39] in a underground station in Barcelona (Spain) using a Wireless Sensor Network (WSN) to know real data of occupancy, temperature, humidity, etc. ... Other example with a WSN is shown by Reena et al. [40] by means of sensors and used to control indoor climate in a Building Automation System (BAS). A WSN could be considered the best way to avoid disturbances related with any alteration of temperature or occupancy information, because as indicated by Oldewurtel et al. [41], the occupancy information is a very important factor to reach a correct building climate control. Furthermore, nowadays these detectors could be harvesters because they would be more easily installed and maintained. Finally, several papers which study different ways to manage the information and control the HVAC system have been reviewed, in order to have a nice comfort conditions but optimizing the energy consumption in the building: Marvuglia et al. [42] combined neuro-fuzzy model for indoor temperature dynamic and automatic regulation, Collotta et al. [43] proposed an artificial neural network to perform indoor temperatures forecast which were used to feed a fuzzy logic control unit, Dragomir et al. [44] identified the most used criteria, related to each modeling step, to define an optimal neural network forecasting tool and Ghadi et al. [45] developed an advanced fuzzy logic controllers in a smart building.

\section{Discussion about MPC as An Useful Tool}

With the appropriate Passive Strategies applied during the design phase will be much easier the next steps. Economic analysis is also fundamental to define the Active Strategies: the more adequate RES and the type of HVAC System to minimize the impact of the weather on the internal environment of the building and guarantee the required comfort levels. Also the occupancy's behaviour will be another key point. It recommends to work together the interrelation between the different fields, defining strategies that add and facilitate the maximum possible energy efficiency and even applying new tools in buildings that help us to achieve nZEBs.

For all this, taking into consideration the different technological advances available nowadays, it is also possible to improve the efficiency of the building management by using Model Predictive Control (MPC). Its use would allow the energy consumption of the buildings to be optimized. For example, managing heating or cooling by means of RES using weather and occupancy forecasts available from different databases and existing modelling applications.

To explain it in a graphic way, we are going to take an example when we use our particular car to move. The difference in fuel consumption is influenced by different variables: depending on the type of vehicle, its design: aerodynamic, weight, tires, etcetera, its consumption will vary widely. The same happens in buildings with the influence of its design depending on its size, orientation, WWR, ... It will also depend on the route we want to drive, type of route: urban, motorway, mountain road as well as traffic conditions such as traffic jams, controls, traffic lights status or number of occupants, luggage weight and others conditions that we cannot control. In the case of buildings, those factors would be weather and occupation conditions. However, as any of us can check when we drive our car every morning, our way of driving, more or less sporting, taking advantage of the inertia to not stop sharply when arriving at a red light or simply depending on the chosen route conditions, it has a significant consequence in the final consumption that we have in our car.

What would happen if in a building we would do the same? With an adequate modelling, we could control its thermal inertia as well as base on a forecast of occupation and climate. This would help us to establish the most convenient "route" to reduce consumption to the maximum and within the most economical time slots. This is the philosophy that proposed in this paper to include the MPC as one more part of the nZEBs.

\section{Conclusions and Future Works}

As it has been justified through the mentioned references, it is currently possible to improve the energy efficiency of any building with the available technologies and tools. But specifically in public and office buildings, the possibilities are huge with a Predictive Control system. It could be possible to manage a HVAC system with source from renewable energies, in an effective way, achieving considerable energy savings, and therefore, reducing $\mathrm{CO}_{2}$ emissions. Our next work will be a review 
of the application of RES in buildings, especially solar collectors used with a radiant floor and high efficiency heat pumps. Furthermore, we will consider developing a modeling of an office building in the Basque Country (Spain) by a building energy performance simulation program, for instance a simulation is proposed with the TRNSYS application after the remodelling of the Basque Country University Vice-rectorate building (Leioa-North of Spain).

\section{References}

1. European Union. Directive 2010/31/EU; European Union: Brussels, Belgium, 2010.

2. European Union. Directive 2002/91/EC; European Union: Brussels, Belgium, 2003.

3. European Union. Directive 2012/27/EU; European Union: Brussels, Belgium, 2012.

4. European Union (EU). 2030 Framework 2013/2135(INI); European Union: Brussels, Belgium, 2014.

5. Loukaidou, K.; Michopoulos, A.; Zachariadis, T. Nearly-Zero Energy Buildings: Cost-Optimal Analysis of Building Envelope Characteristics. Procedia Environ. Sci. 2017, 38, $20-27$.

6. Aste, N.; Adhikari, R.S.; Del Pero, C.; Leonforte, F. Multi-functional Integrated System for Energy Retrofit of Existing Buildings: A Solution Towards nZEB Standards. Energy Procedia 2017, 105, 2811-2817.

7. Barthelmes, V.M.; Becchio, C.; Bottero, M.C.; Corgnati, S.P. The Influence of Energy Targets and Economic Concerns in Design Strategies for a Residential Nearly-Zero Energy Building. Buildings 2014, 4, 937-962.

8. Murano, G.; Ballarini, I.; Dirutigliano, D.; Primo, E.; Corrado, V. The significant imbalance of nZEB energy need for heating and cooling in Italian climatic zones. Energy Procedia 2017, 126, 258-265.

9. Cornaro, C.; Pierro, M.; Puggioni, V.A.; Roncarati, D. Outdoor Characterization of Phase Change Materials and Assessment of Their Energy Saving Potential to Reach NZEB. Buildings 2017, 55, 7.

10. Cornaro, C.; Basciano, G.; Puggioni, V.A.; Pierro, M. Energy Saving Assessment of Semi-Transparent Photovoltaic Modules Integrated into NZEB. Buildings 2017, 9, 7.

11. Kurnitski, J.; Saari, A.; Kalamees, T.; Vuolle, M.; Niemelä, J.; Tark, T. Cost optimal and nearly zero (nZEB) energy performance calculations for residential buildings with REHVA definition for nZEB national implementation. Energy Build. 2011, 43, 3279-3288.

12. Kang, H.J. Development of an Nearly Zero Emission Building (nZEB) Life Cycle Cost Assessment Tool for Fast Decision Making in the Early Design Phase. Energies 2017, 59, 10.

13. Karlessi, T.; Kampelis, N.; Kolokotsa, D.; Santamouris, M.; Standardi, L.; Isidori, D.; Cristalli, C. The concept of smart and NZEB buildings and the integrated design approach. Procedia Eng. 2017, 180, 1316-1325.

14. Péan, T.Q.; Ortiz, J.; Salom, J. Impact of Demand-Side Management on Thermal Comfort and Energy Costs in a Residential nZEB. Buildings 2017, 37, 7.

15. Guillén-Lambea, S.; Rodríguez-Soria, B.; Marín, J.M. Comfort settings and energy demand for residential nZEB in warm climates. Appl. Energy 2017, 202, 471-486.

16. Keltsch, M.; Lang, W.; Auer, T. Nearly Zero Energy Standard for Non-Residential Buildings with high Energy Demands-An Empirical Case Study Using the State-Related Properties of BAVARIA. Buildings 2017, 25, 7.

17. Cellura, M.; Ciulla, G.; Guarino, F.; Longo, S. Redesign of a Rural Building in a Heritage Site in Italy: Towards the Net Zero Energy Target. Buildings 2017, 68, 7.

18. Monteiro, J.; Castro, O. Application of the nZEB methodology in the retrofitting of a typical Portuguese dwelling from the 50's. In Proceedings of the 11th REHVA World Congress (CLIMA 2013), Prague, Czech Republic, 16-19 June 2013.

19. Becchio, C.; Dabbene, P.; Fabrizio, E.; Monetti, V.; Filippi, M. Cost optimality assessment of a single family house: building and technical systems solutions for the nZEB target. Energy Build. 2015, 90, 173-187.

20. Adhikari, R.S.; Aste, N.; del Pero, C.; Manfren, M. Net Zero Energy Buildings: Expense or Investment? Energy Procedia 2012, 14, 1331-1336.

21. García, C.E.; Prett, D.M.; Morari, M. Model predictive control: Theory and practice-A survey. Automatica 1989, 25, 335-348.

22. Cho, S.H.; Zaheer-uddin, M. Predictive control of intermittently operated radiant floor heating systems. Energy Convers. Manag. 2003, 44, 1333-1342.

23. Roberts, S. Altering existing buildings in the UK. Energy Policy 2008, 36, 4482-4486.

24. Kneifel, J. Life-cycle carbon and cost analysis of energy efficiency measures in new commercial buildings. Energy Build. 2010, 42, 333-340. 
25. Oldewurtel, F.; Parisio, A.; Jones, C.; Gyalistras, D.; Gwerder, M.; Stauch, V.; Lehmann, B.; Morari, M. Use of model predictive control and weather forecasts for energy efficient building climate control. Energy Build. 2011, 45, 15-27.

26. Široký, J.; Oldewurtel, F.; Cigler, J.; Prívara, S. Experimental analysis of model predictive control for an energy efficient building heating system. Appl. Energy 2011, 88, 3079-3087.

27. Cigler, J.; Gyalistras, D.; Široký, J.; Tiet, V.-N.; Ferkla, L. Beyond theory: the challenge of implementing Model Predictive Control in buildings. In Proceedings of the 11th REHVA World Congress (CLIMA 2013), Prague, Czech Republic, 16-19 June 2013.

28. Fabietti, L. Control of HVAC Systems via Explicit and Implicit MPC: An Experimental Case Study. Master's Degree, Project of the KTH Electrical Engineering - No. XE-EE-RT 2014:006, April 2014.

29. Xiwang, L.; Wen, J. Review of building energy modeling for control and operation. Renew. Sustain. Energy Rev. 2014, 37, 517-537.

30. De Coninck, R.; Helsen, L. Practical implementation and evaluation of model predictive control for an office building in Brussels. Energy Build. 2016, 111, 290-298.

31. Ruparathna, R.; Hewage, K.; Sadiq, R. Improving the energy efficiency of the existing building stock: A critical review of commercial and institutional buildings. Renew. Sustain. Energy Rev. 2015, 53, 1032-1045.

32. Harish, V.S.K.V.; Kumar, A. A review on modeling and simulation of building energy systems. Renew. Sustain. Energy Rev. 2015, 56, 1272-1292.

33. Chandel, S.S.; Sharma, A.; Marwaha, B.M. Review of energy efficiency initiatives and regulations for residential buildings in India. Renew. Sustain. Energy Rev. 2016, 54, 1443-1458.

34. Santos-Herrero, J.M.; Lopez-Guede, J.M.; Flores, I.; Sala, J.M. An ongoing review on building energy efficiency improvement systems. In Proceedings of the IV European Conference on Renewable Energy Systems, Istanbul, Turkey, 28-31 August 2016.

35. Carrascal, E.; Garrido, I.; Garrido, A.J.; Sala, J.M. Optimization of the Heating System Use in Aged Public Buildings via Model Predictive Control. Energies 2016, 9, 251.

36. Ascione, F.; Bianco, N.; De Stasio, C.; Mauro, G.M.; Vanoli, G.P. Simulation-based model predictive control by the multi-objective optimization of building energy performance and thermal comfort. Energy Build. 2015, 111, 131-144.

37. Hu, Q.; Oldewurtel, F.; Balandat, M.; Vrettos, E.; Zhou, D.; Tomlin, C.J. Building Model Identification during Regular Operation-Empirical Results and Challenges. In Proceedings of the IEEE American Control Conference, Boston, MA, USA, 6-8 July 2016.

38. Sturzenegger, D.; Gyalistras, D.; Morari, M.; Smith, R.S. Model Predictive Climate Control of a Swiss Office Building: Implementation, Results, and Cost-Benefit Analysis. Contr. Syst. Technol. 2015, $24,1$.

39. Vaccarini, M.; Giretti, A.; Tolve, L.C.; Casals, M.M. Model predictive energy control of ventilation for underground stations. Energy Build. 2016, 116, 326-340.

40. Reena, M.; Mathew, A.T.; Jacob, L. Energy Efficient Wireless Networked Building Automation System Controlled by Real Occupancy. In Proceedings of the TENCON 2015 - IEEE Region 10 Conference, Macau, China, 1-4 November 2015.

41. Oldewurtel, F.; Sturzenegger, D.; Morari, M. Importance of occupancy information for building climate control; Appl. Energy 2012, 101, 521-532.

42. Marvuglia, A.; Messineo, A.; Nicolosi, G. Coupling a neural network temperature predictor and a fuzzy logic controller to perform thermal comfort regulation in an office building. Build. Environ. 2014, 72, 287299.

43. Collotta, M.; Messineo, A.; Nicolosi, G.; Pau, G. A Dynamic Fuzzy Controller to Meet Thermal Comfort by Using Neural Network Forecasted Parameters as the Input. Energies 2014, 7, 4727-4756.

44. Dragomir, O.E.; Dragomir, F.; Stefan, V.; Minca, E. Adaptive Neuro-Fuzzy Inference Systems as a Strategy for Predicting and Controling the Energy Produced from Renewable Sources. Energies 2015, 8, 13047-13061.

45. Ghadi, Y.Y.; Rasul, M.G.; Khan, M.M.K. Design and development of advanced fuzzy logic controllers in smart buildings for institutional buildings in subtropical Queensland. Renew. Sustain. Energy Rev. 2015, 54, 738-744.

(C) 2018 by the authors. Licensee MDPI, Basel, Switzerland. This article is an open access article distributed under the terms and conditions of the Creative Commons Attribution (CC BY) license (http://creativecommons.org/licenses/by/4.0/). 